\title{
BMJ Open Factors associated with knowledge and attitude towards adult cardiopulmonary resuscitation among healthcare professionals at the University of Gondar Comprehensive Specialized Hospital, Northwest Ethiopia: an institutional-based cross-sectional study
}

Abraham Tarekegn Mersha (D) , Amare Haile Kiros Gebre Egzi, Hailu Yimer Tawuye, Nigussie Simeneh Endalew

To cite: Mersha AT, Gebre Egzi AHK, Tawuye HY, et al. Factors associated with knowledge and attitude towards adult cardiopulmonary resuscitation among healthcare professionals at the University of Gondar Comprehensive Specialized Hospital, Northwest Ethiopia: an institutional-based cross-sectional study. BMJ Open 2020;10:e037416. doi:10.1136/ bmjopen-2020-037416

- Prepublication history and additional material for this paper are available online. To view these files, please visit the journal online (http://dx.doi org/10.1136/bmjopen-2020037416).

Received 05 February 2020 Revised 08 August 2020 Accepted 18 August 2020

Check for updates

(C) Author(s) (or their employer(s)) 2020. Re-use permitted under CC BY-NC. No commercial re-use. See rights and permissions. Published by BMJ.

Anesthesia, University of Gondar College of Medicine and Health Sciences, Gondar, Amhara, Ethiopia

Correspondence to Abraham Tarekegn Mersha; abrahamtm2006@gmail.com

\section{ABSTRACT}

Objective This study was conducted to assess the factors associated with knowledge and attitude towards adult cardiopulmonary resuscitation (CPR) among health professionals at the University of Gondar Hospital, Northwest Ethiopia.

Study design An institutional-based cross-sectional study was conducted from 15 February to 15 March 2018. Both bivariable and multivariable logistic regression analyses were used to identify factors associated with knowledge and attitude level of health professionals towards CPR. Variables with a $p$ value less than $<0.2$ in the bivariable analysis were fitted into the multivariable analysis. In the multivariable analysis, variables with a $p$ value $<0.05$ were considered statistically significant.

Setting University of Gondar Comprehensive Specialized Hospital, Northwest Ethiopia.

Participants A total of 406 health professionals (physicians, nurses, anaesthetists, health officers and midwives) were included.

Results Among the study participants, $25.1 \%(95 \% \mathrm{Cl}$ 21.2 to 29.3$)$ had good knowledge and $60.8 \%(95 \% \mathrm{Cl}$ 55.9 to 65.5 ) had good attitude towards adult CPR. Work experience (adjusted OR (AOR): $5.02,95 \% \mathrm{Cl} 1.25$ to 20.20), number of work settings (AOR: $6.52,95 \% \mathrm{Cl} 2.76$ to 15.41 ), taking CPR training (AOR: $2.76,95 \% \mathrm{Cl} 1.40$ to 5.42), exposure to cardiac arrest case (AOR: $2.16,95 \% \mathrm{Cl}$ 1.14 to 4.07 ) and reading CPR guidelines (AOR: 5.57, $95 \% \mathrm{Cl} 2.76$ to 11.20 ) were positively associated with good knowledge. Similarly, taking CPR training (AOR: 1.74, $95 \% \mathrm{Cl} 1.42$ to 1.53 ) and reading CPR guidelines (AOR: $2.74,95 \% \mathrm{Cl} 1.55$ to 4.85 ) were positively associated with good attitude.

Conclusions The level of knowledge and attitude of health professionals towards adult CPR was suboptimal. Health professionals who were taking CPR training and reading CPR guidelines had good knowledge and attitude towards CPR. In addition, work experience, number of work settings and exposure to cardiac arrest case had a
Strengths and limitations of this study

The study was conducted including different health professionals.

- This study used standardised and structured tools to assess knowledge and attitude level of health professionals.

- The study did not investigate the practice level of professionals.

- The study might be subjected to social desirability bias.

positive association with CPR knowledge. Thus, providing regular CPR training and work setting rotations is highly crucial.

\section{INTRODUCTION}

Cardiopulmonary arrest is the most critical medical and surgical emergency. ${ }^{1}$ It is a major health problem worldwide and is common especially in areas with low income, which may be associated with inadequate medical care and facilities. ${ }^{23}$ Cardiac arrest may occur in and out of hospitals ${ }^{4}$ due to different reasons, such as traumatic injuries of any cause, cardiac diseases and stroke. ${ }^{5-7}$

Cardiopulmonary resuscitation (CPR) is the standard treatment used for the management of cardiac arrest and combines chest compressions with ventilation. ${ }^{8}$ Adequate knowledge and skills of healthcare givers with regard to the manoeuvres and techniques for CPR prevents irreversible organ damages and improves the chances of survival of cardiac arrest victims. ${ }^{89}$ As a result, CPR 
requires comprehensive efforts, with adequate knowledge and skills as well as interests and positive attitude to help victims. ${ }^{10}$ Thus, health professionals should have basic knowledge on the fundamental aspects of basic life support (BLS) and advanced cardiac life support (ACLS) and perform high-quality CPR to improve survival from cardiac arrest. ${ }^{1-14}$ However, knowledge and skills gap among health professionals with regard to CPR and management strategies for cardiac arrest is a global problem. ${ }^{615}$

Among Kuwait dental physicians, age, gender, years of experience and formal CPR training were correlated with CPR knowledge. ${ }^{16}$ BLS and ACLS knowledge and skills tend to degrade after some time, and regular training and practice as a refresher course have been recommended in different studies. ${ }^{17-19}$

Some of the previous studies showed that health professionals have good knowledge in BLS/ACLS, such as in the use of automated external defibrillator, compression rate, compression to ventilation ratio and checking the pulse for signs of life. ${ }^{180-22}$ Some literature also suggests that frequent training is important to retain good knowledge and attitude towards CPR. ${ }^{1723-25}$

A study among Singapore primary care physicians showed that those who were less than 50 years old were more trained in BLS and ACLS and had good knowledge than those older than 50 years old. ${ }^{20}$ Similarly, a crosssectional study in a Jamaican university hospital indicated that physician seniority was inversely related to knowledge scores. ${ }^{21}$ Another hospital-based study in Malaysia revealed that being a junior in clinical practice significantly increased the level of confidence in performing CPR. ${ }^{17}$

In a Nepal study on clinical faculty members (dental and basic sciences members, house officers, nurses and health assistants), knowledge score was significantly higher in those who had taken CPR training of 5 years' duration than those who had taken training of more than 5 years' duration and those who had not taken CPR training at all. ${ }^{23}$ In addition, another study in Pakistan reported that the reason for inability and underconfidence in initiating BLS among radiology residents and radiologists was inadequate training. ${ }^{26}$

Finally, a study conducted among nurses in Ethiopia showed that those who had 5-10 years of clinical experiences, were working in different wards and were taking BLS training were more knowledgeable compared with their counterparts. ${ }^{27}$

This study aimed to assess the factors associated with knowledge and attitude level of health professionals towards CPR at the University of Gondar Comprehensive Specialized Hospital, Northwest Ethiopia.

\section{MATERIALS AND METHODS}

\section{Study setting and population}

An institutional-based cross-sectional study was conducted from 15 February to 15 March 2018. All anaesthetists, health officers, nurses, midwives, psychiatry nurses and physicians who were working at the University of Gondar Comprehensive Specialized Hospital during the data collection period were included in this study. The University of Gondar Comprehensive Specialized Hospital is one of the medical schools in Ethiopia and is currently serving a population of around five million.

\section{Sample size, sampling technique and procedure}

Single population proportion formula was used to determine the sample size. It was calculated by considering 95\% CI, a $5 \%$ margin of error and $50 \%$ as a proportion of good knowledge about CPR. Finally, a sample size of 424 was obtained after adding a $10 \%$ non-response rate. Stratified sampling followed by simple random sampling technique was employed to reach study participants. Initially, health professionals were stratified into different categories based on their field of study. A total of 843 healthcare professionals were obtained from the College of Medicine and Health Science and the University of Gondar Comprehensive Specialized Hospital human resources department. The total number of health professionals included in the study was proportional to the number of health professionals in each profession. Finally, a simple random sampling technique was employed to select study participants.

\section{Operational definition}

- Knowledge on CPR: study participants who answered $80 \%$ and above correct answers to the knowledge questions on CPR were considered to have good knowledge, while participants who scored below $80 \%$ were considered to have poor knowledge. ${ }^{2228-30}$

- Attitude towards CPR: study participants who answered $80 \%$ and above correct answers to the attitude questions on CPR were considered to have positive attitude, whereas those who answered below $80 \%$ were considered to have poor attitude. ${ }^{22}{ }^{28}$ Each item of the attitude questionnaire was measured on a 5-point Likert scale, which has a total of 13 items, with a minimum total score of 13 and a maximum of 65 , and expressed in percentage.

- Number of work settings: health professionals' number of work areas, whether working in one area or in more than one work area, at the University of Gondar Comprehensive Specialized Hospital.

- Work experience: health professionals' total years of experience after graduation and starting work.

- Exposure to cardiac arrest case. exposure of health professionals to cardiac arrest victims during their entire work experience.

- Reading CPR guidelines: health professionals' habit or experience of reading CPR guidelines at any time during their work experience.

- Training on CPR: health professionals taking CPR training for the last 2 years were considered to have regular training. 


\section{Data collection procedures}

Three data collectors and one supervisor were recruited for the study. An English version of the self-administered questionnaire was used to collect data from the professionals. A total of 13 attitude and 28 knowledge questions were used to assess healthcare professionals' level of attitude and knowledge, respectively. The questionnaire was derived from a standard reference American Heart Association (AHA) guidelines for CPR and emergency cardiac care based on the course content of the 2015 AHA BLS and ACLS and were validated by the AHA. ${ }^{22} 2931$ The sum of correct responses for the 28 knowledge questions was computed and expressed in percentage to categorise whether study participants have good or poor knowledge. Similarly, attitude was measured on a 5-point Likert scale and expressed in percentage to categorise whether study participants have positive or negative attitude. Reliability of the tool was checked using reliability coefficient (Cronbach's alpha) and was 0.88 for knowledge and 0.86 for attitude (online supplemental files 1-4).

\section{Data quality control}

To ensure quality of data, pretest was done on 22 (5\% of the sample size) health professionals at the Felege Hiwot Referral Hospital. Based on the findings amendments were made on the questionnaires. A 1-day training was given to the data collectors and the supervisor on the aim or objective of the study, how to approach study subjects, how to use the questionnaire, and how to supervise and collect data.

The principal investigator and the supervisor checked the collected data for completeness, accuracy and clarity. Daily supervision and feedback were done by the principal investigator and the supervisor during the entire period of data collection. Finally coding, data entry, data cleaning and crosschecking were done before data analysis.

\section{Data analysis and interpretation}

Epi Info V.7 and SPSS V.20 were used for data entry and analysis, respectively. Descriptive statistics were carried out and the results were presented using text, tables and graphs. Both bivariable and multivariable binary logistic regression analyses were used to identify factors associated with level of knowledge and attitude of health professionals. Variables with a $\mathrm{p}$ value less than $<0.2$ in the bivariable analysis were fitted into the multivariable logistic regression analysis using the 'enter' method. Both crude OR and adjusted OR (AOR) with the corresponding 95\% CI were calculated to show the strength of association. In the multivariable analysis, variables with a $p$ value of $<0.05$ were considered statistically significant. Hosmer-Lemeshow test was used to check for goodness of fit.

\section{Patient and public involvement}

The questionnaires used for this study were developed by the researchers by review of different literature and
Table 1 Sociodemographic characteristics of health professionals working at the University of Gondar Comprehensive Specialized Hospital, Northwest Ethiopia, $2018(\mathrm{~N}=406)$

\begin{tabular}{lrr}
\hline Variables & Frequency (n) & Percentage \\
\hline Age (years) & & \\
\hline $20-29$ & 246 & 60.6 \\
$30-39$ & 151 & 37.2 \\
$\geq 40$ & 9 & 2.2 \\
\hline Sex & & \\
\hline Male & 262 & 64.5 \\
\hline Female & 144 & 35.5 \\
\hline Religion & & \\
\hline Orthodox & 329 & 81.0 \\
\hline Muslim & 40 & 9.9 \\
\hline Protestant & 32 & 7.9 \\
\hline Catholic & 5 & 1.2 \\
\hline Occupation & & \\
\hline Physician & 111 & 27.3 \\
\hline Nurse & 215 & 52.9 \\
\hline Health officer & 6 & 1.5 \\
\hline Anaesthetist & 17 & 4.1 \\
\hline Midwife & 45 & 11.1 \\
\hline Psychiatry nurse & 12 & 3.0 \\
\hline Educational status & & \\
\hline BSc degree & 283 & 69.7 \\
\hline Master's degree & 34 & 8.4 \\
\hline Resident & 63 & 15.5 \\
\hline Specialist & 26 & 6.4 \\
\hline
\end{tabular}

guidelines. Patients were not directly involved in the study. The results will be used by health researchers and policy makers of the country.

\section{RESULTS}

Sociodemographic characteristics of the study participants

A total of 406 study participants were involved in the study, with a response rate of $95.7 \%$. The median age of the study participants was $28(\mathrm{IQR}=6)$ years. Around two-thirds $(65 \%)$ of the participants were male and most $(81.0 \%)$ were orthodox in religion.

With regard to their profession, 111 (27.3\%) were physicians, $215(52.9 \%)$ nurses, $6(1.5 \%)$ health officers, $17(4.1 \%)$ anaesthetists, $45(11.1 \%)$ midwives and 12 $(3.0 \%)$ psychiatry nurses (table 1$)$.

\section{Work-related characteristics of study participants}

More than half $(239,58.9 \%)$ of the study participants had 2-5 years of work experience. More than two-thirds (287, $70.7 \%$ ) worked only in one ward/outpatient department, whereas $212(52.2 \%)$ worked in different wards. More 
than half $(220,54.2 \%)$ of the study participants had encountered cardiac arrest case in their work area and $145(65.9 \%)$ of them resuscitated those cardiac arrest victims (table 2). On the other hand, 75 (34.1\%) study participants did not resuscitate the victim due to different reasons (figure 1).

\section{Knowledge level of health professionals about adult CPR}

Only 102 (25.1\%) (95\% CI 21.2 to 29.3) participants had good knowledge about adult CPR. The median knowledge score of the study participants was 14.5 (IQR=13). The level of knowledge differs across different professions (figure 2).

The most correctly answered question by study participants was estimation of effectiveness of CPR (328, $80.8 \%$ ), followed by the importance of chest compression during CPR (324, 79.8\%). The least answered question was the first step for CPR for an adult unresponsive to shouting and shaking with hands among health professionals alone at the health facility $(138,34.0 \%)$, followed by correct sequence of adult BLS according to the 2015 AHA guidelines (141, 34.7\%) (table 3).

\section{Attitude level of health professionals about CPR}

Of the study participants, $247(60.8 \%)$ (95\% CI 55.9 to $65.5)$ had good attitude. The median attitude score of health professionals towards adult CPR was 53 (IQR=10). Based on profession, $100(90.1 \%)$ physicians and 16 $(94.1 \%)$ anaesthetists had better attitude towards adult CPR compared with other professions (figure 3).

Most health professionals believe that BLS/ACLS training should be given before practising CPR. In addition, some of the professionals strongly agreed that they should be recertified on CPR course every 2 years (table 4).

\section{Factors associated with knowledge of health professionals}

In the bivariable logistic regression analysis, variables such as sex, age, work experience, number of work settings, educational status, exposure to cardiac arrest case, CPR training and reading international CPR guidelines were significant. However, only work experience, taking CPR training, number of work settings, exposure to cardiac arrest case and reading international CPR guidelines were significantly associated with good knowledge.

Accordingly, health professionals who had greater than 5 years of work experience were 5.02 times more likely to have good knowledge than health professionals who had less than 2 years of work experience (AOR: 5.02 , 95\% CI 1.25 to 20.20). Similarly, the odds of having good knowledge towards adult CPR were 6.52 times (AOR: 6.52, 95\% CI 2.76 to 15.41) higher among health professionals working in more than one work area as compared with health professionals with exposure in only one work area. The study also revealed that the likelihood of having good knowledge towards adult CPR was 2.76 times (AOR: 2.76, $95 \%$ CI 1.40 to 5.42) higher among health professionals who had taken CPR training as compared with
Table 2 Work-related characteristics of health professionals working at the University of Gondar Comprehensive Specialized Hospital, Northwest Ethiopia, $2018(\mathrm{~N}=406)$

\begin{tabular}{|c|c|c|}
\hline Variables & Frequency (n) & Percentage \\
\hline \multicolumn{3}{|l|}{ Work experience (years) } \\
\hline$<2$ & 53 & 13.1 \\
\hline $2-5$ & 239 & 58.9 \\
\hline$>5$ & 114 & 28.0 \\
\hline \multicolumn{3}{|l|}{ Specific work area* } \\
\hline Emergency & 88 & 21.7 \\
\hline Wardst & 212 & 52.2 \\
\hline Recovery room & 33 & 8.1 \\
\hline Intensive care unit & 62 & 15.3 \\
\hline Operation room & 76 & 18.7 \\
\hline Outpatient department & 172 & 42.4 \\
\hline Others $¥$ & 27 & 6.7 \\
\hline \multicolumn{3}{|l|}{ Number of work settings } \\
\hline $\begin{array}{l}\text { Works only in one work } \\
\text { area }\end{array}$ & 287 & 70.7 \\
\hline $\begin{array}{l}\text { Works in more than one } \\
\text { work area }\end{array}$ & 119 & 29.3 \\
\hline \multicolumn{3}{|c|}{ Basis of knowledge about CPR ${ }^{*}$} \\
\hline Reading & 114 & 38.3 \\
\hline University/college course & 234 & 78.7 \\
\hline Seminar presentation & 85 & 28.6 \\
\hline Preservice training & 26 & 8 \\
\hline Inservice training & 85 & 28.6 \\
\hline \multicolumn{3}{|c|}{ Encountered cardiac arrest case } \\
\hline Yes & 220 & 54.2 \\
\hline No & 186 & 45.8 \\
\hline \multicolumn{3}{|c|}{$\begin{array}{l}\text { Did you resuscitate the cardiac arrest victim? } \\
(n=220)\end{array}$} \\
\hline Yes & 145 & 65.9 \\
\hline No & 75 & 34.1 \\
\hline \multicolumn{3}{|l|}{ CPR training } \\
\hline Yes & 158 & 38.9 \\
\hline No & 248 & 61.1 \\
\hline \multicolumn{3}{|c|}{ When did you take CPR training? $(n=158)$} \\
\hline$\leq 2$ years ago & 43 & 27.2 \\
\hline$>2$ years ago & 115 & 72.8 \\
\hline \multicolumn{3}{|l|}{ Reading CPR guidelines } \\
\hline Yes & 150 & 36.9 \\
\hline No & 256 & 63.1 \\
\hline
\end{tabular}

*Multiple response.

†Wards (medical, surgical, orthopaedic, paediatrics, obstetrics, gynaecology and psychiatry).

fOthers (dental, optometry, pathology and radiology). $\mathrm{CPR}$, cardiopulmonary resuscitation. 


\section{Reason to not resuscitate cardiac arrest victims}

- No of study participants

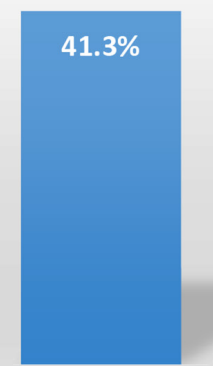

Inadequate

knowledge of

CPR

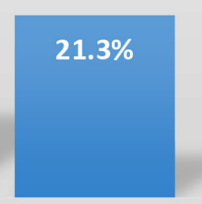

Lack of confidence

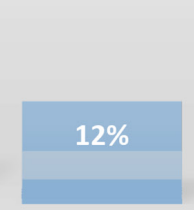

Irreversible cause of cardiac arrest

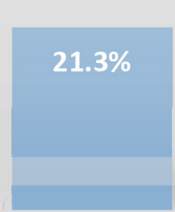

Absence of organised resuscitation team

Figure 1 Reasons not to resuscitate cardiac arrest victims according to health professionals at the University of Gondar Comprehensive Specialized Hospital, Northwest Ethiopia, $2018(n=75)$. CPR, cardiopulmonary resuscitation.

their counterparts. Health professionals who had exposure to cardiac arrest case were 2.16 times (AOR: 2.16, $95 \%$ CI 1.14 to 4.07 ) more likely to be knowledgeable than those who had no cardiac arrest exposure. Finally, health professionals who read international CPR guidelines were 5.57 times more likely to have good knowledge than those who did not read international CPR guidelines (AOR: 5.57, 95\% CI 2.76 to 11.20 ) (table 5).

\section{Factors associated with attitude of health professionals}

Both bivariable and multivariable logistic regression analyses were done to see the effect of selected characteristics on the attitude of health professionals. Variables such as age, sex, number of work settings, educational status, CPR training and reading CPR guidelines had significant association with attitude of health professionals in the bivariable analysis. However, only CPR training and reading CPR guidelines were significantly associated with good attitude in the multivariable analysis.

The likelihood of having good attitude towards adult CPR was 1.74 times (AOR: 1.74, 95\% CI 1.42 to 3.53) higher among health professionals who had taken CPR training as compared with health professionals who had not taken CPR training. Similarly, the likelihood of having good attitude towards adult CPR was 2.74 times (AOR: 2.74, 95\% CI 1.55 to 4.85 ) higher among health

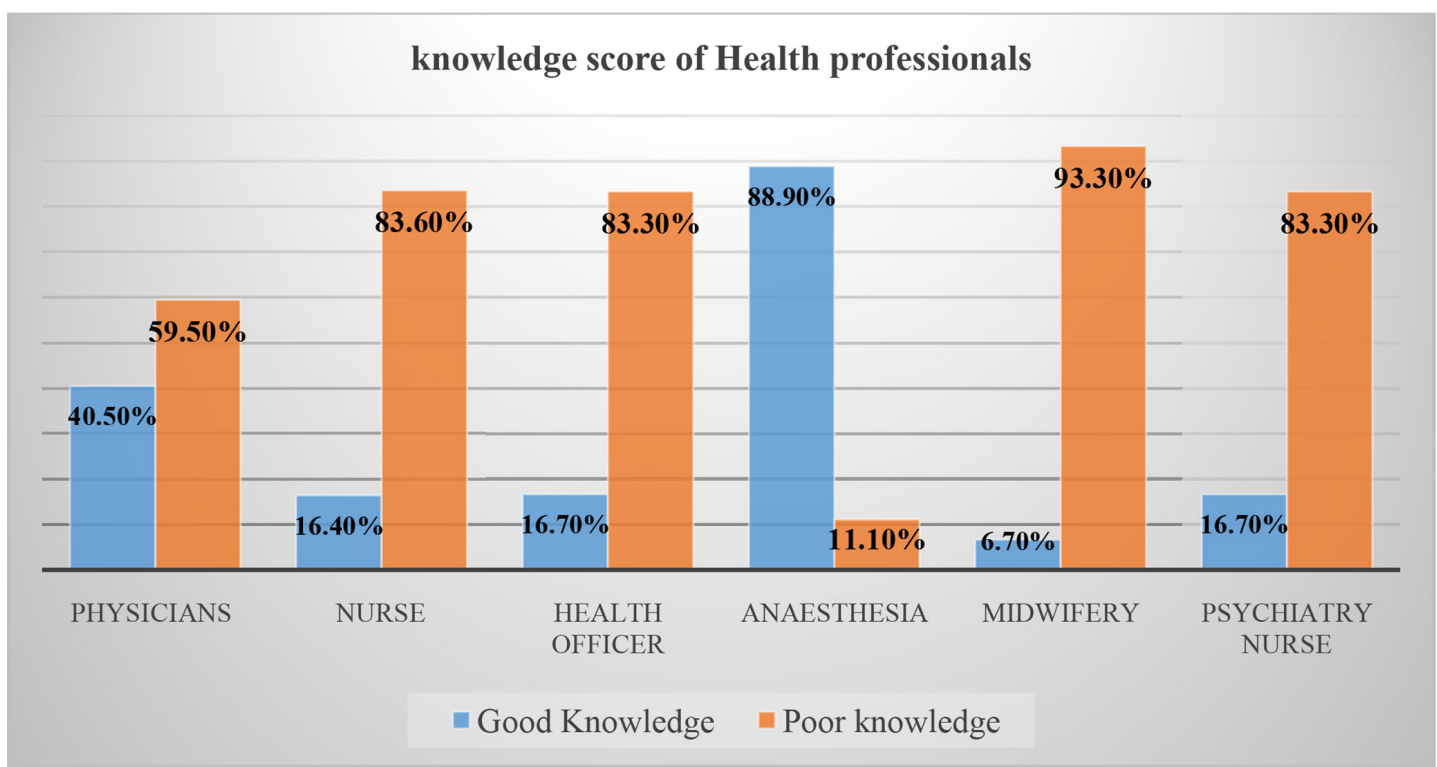

Figure 2 Knowledge level of health professionals in each department at the University of Gondar Comprehensive Specialized Hospital, Northwest Ethiopia, 2018 (N=406). 
Table 3 Correct responses to knowledge questions by health professionals at the University of Gondar Comprehensive Specialized Hospital, Northwest Ethiopia, 2018 ( $N=406)$

\begin{tabular}{|c|c|c|}
\hline Questions & Frequency & Percentage \\
\hline The cause of reversible cardiac arrest & 229 & 56.4 \\
\hline Importance of chest compression during CPR & 324 & 79.8 \\
\hline Not the component of high-quality CPR & 172 & 42.4 \\
\hline The steps of adult chain of survival & 187 & 46.1 \\
\hline An indication to stop CPR & 225 & 55.4 \\
\hline The effectiveness of CPR can be estimation & 328 & 80.8 \\
\hline The correct sequence of the BLS steps, according to the 2015 AHA guidelines & 141 & 34.7 \\
\hline $\begin{array}{l}\text { Immediate action for an adult victim not responding to shaking and shouting (note: if multiple } \\
\text { rescuers are present) }\end{array}$ & 254 & 62.6 \\
\hline First step for an unresponsive adult person (note: if you are alone at that place) & 138 & 34.0 \\
\hline The location of hands during chest compression for adult victim & 269 & 66.3 \\
\hline Site of pulse check in an adult cardiac arrest & 309 & 76.1 \\
\hline $\begin{array}{l}\text { For an adult victim not responding to you even after shaking and shouting, the time to check for } \\
\text { pulse }\end{array}$ & 191 & 47 \\
\hline The compression to ventilation ratio according to adult BLS AHA 2015 guidelines & 186 & 45.8 \\
\hline The recommended rate of effective chest compression & 158 & 38.9 \\
\hline The recommended chest compression depth for adults according to AHA 2015 & 236 & 58.1 \\
\hline Signs of airway obstruction & 323 & 79.6 \\
\hline The manoeuvre used to open airway & 291 & 71.7 \\
\hline The rescuers switch roles when performing two-rescuer CPR & 154 & 37.9 \\
\hline The breathing rate in an adult with an advanced airway in place during two-rescuer CPR & 174 & 42.9 \\
\hline Non-shockable cardiac arrest & 223 & 54.9 \\
\hline Defibrillation is indicated for documented occurrence & 212 & 52.2 \\
\hline The defibrillator pads placement on an adult victim & 264 & 65.0 \\
\hline Recommendations during the use of defibrillator & 180 & 44.3 \\
\hline Drug and dose during shockable cardiac arrest & 185 & 45.6 \\
\hline Drug used during CPR in non-shockable cardiac arrest & 178 & 43.8 \\
\hline The recommended intravenous fluid during CPR & 286 & 70.4 \\
\hline $\begin{array}{l}\text { A type of equipment used to monitor the ventilation rate, quality of CPR and return of } \\
\text { spontaneous circulation }\end{array}$ & 214 & 52.7 \\
\hline After return of spontaneous circulation from CPR, the postresuscitation care & 218 & 53.7 \\
\hline
\end{tabular}

AHA, American Heart Association; BLS, basic life support; CPR, cardiopulmonary resuscitation.

professionals who read CPR guidelines as compared with health professionals who did not read CPR guidelines (table 6).

\section{DISCUSSION}

Health professionals are believed to be knowledgeable, have good attitude and are competent in caring for patients. In hospitals deterioration of patients can be gradual and preventable if health professionals manage their patients closely using their knowledge and skills in resuscitation. $^{89}$

Cardiopulmonary arrest is a major health problem worldwide and is common especially in areas with low income, which may be associated with inadequate medical care and facilities. ${ }^{2}{ }^{3}$ Hence good CPR knowledge and favourable attitude are extremely important in preventing cardiac arrest and reviving the life of a patient who suddenly collapsed. However, health professionals often fail to provide high-quality CPR. Also, poor-quality CPR has been shown to have similar outcomes to patients receiving no $\mathrm{CPR} .{ }^{32}$

In the current study, the knowledge level of health professionals towards adult CPR was 25.1\% (95\% CI 21.2 to 29.3). The finding is lower compared with other studies done in Kuwait $(36 \%),{ }^{16}$ Jamaica $(46 \%),{ }^{17}$ Pakistan $(44.85 \%)^{26}$ and Nigeria (36.9\%). ${ }^{24}$ The possible explanation for this variation might be that the current study was conducted including different health professionals, while 


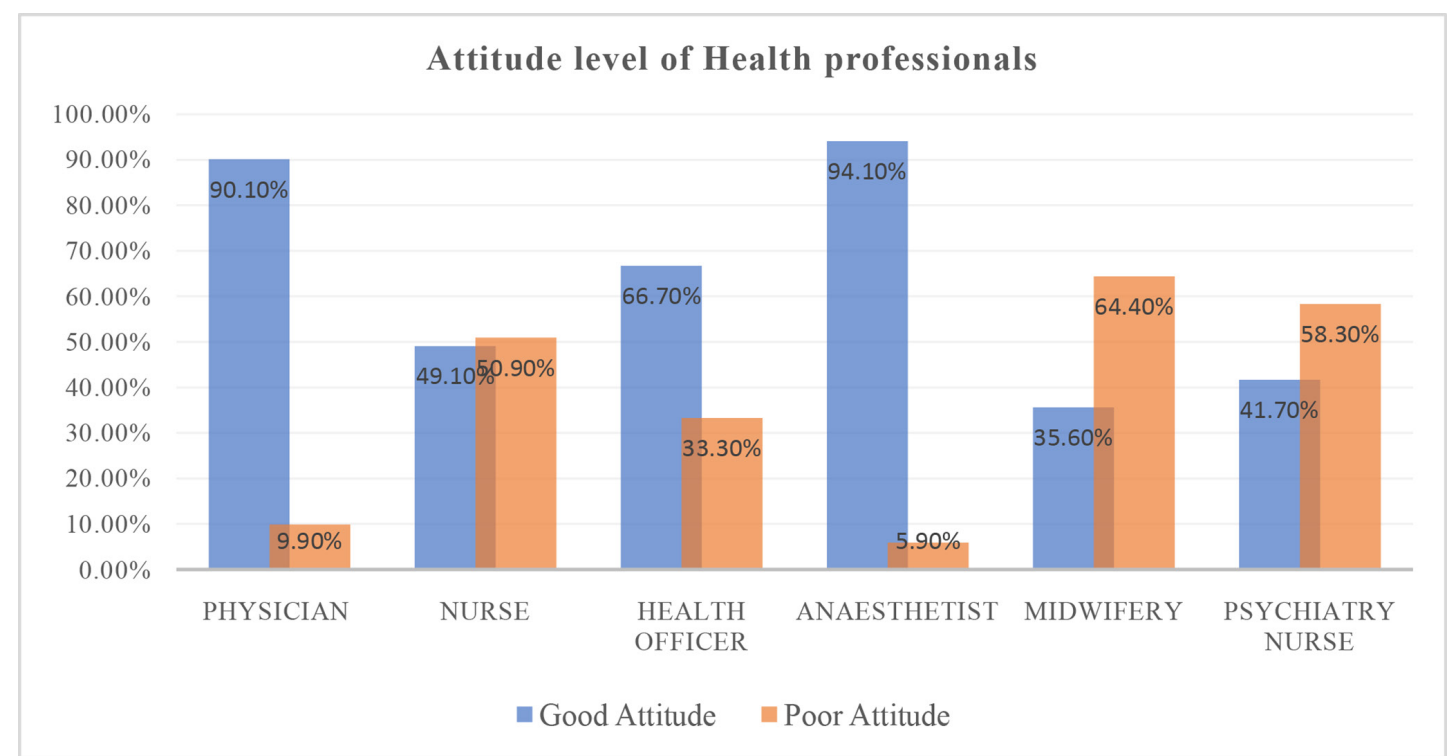

Figure 3 Attitude level of health professionals in each department at the University of Gondar Comprehensive Specialized Hospital, Northwest Ethiopia, 2018 ( $N=406)$.

the abovementioned studies were conducted only among junior medical practitioners. In addition, the study participants in Kuwait and Pakistan had taken regular CPR training every 2 years, while participants in the current study were not taking regular CPR training every 2 years.

However, in this study, knowledge level was higher than in studies done in Addis Ababa, Ethiopia $(6.7 \%)^{33}$ and
South Africa $(11 \%) .^{30}$ The possible explanation might be because half of the study participants in Addis Ababa had less than 5 years of work experience and also that most of the participants (84\%) were BSc holders. The study also used the highest cut-off point as a pass mark to determine level of knowledge. Also, in a South African study the number of trained professionals was lower than

Table 4 Responses to attitude questions by health professionals at the University of Gondar Comprehensive Specialized Hospital, Northwest Ethiopia, 2018 ( $\mathrm{N}=406)$

\begin{tabular}{|c|c|c|c|c|c|}
\hline \multirow[b]{2}{*}{ Attitude questions } & \multicolumn{5}{|c|}{$\begin{array}{l}\text { Health professionals' response to attitude questions on } \\
\text { CPR, n (\%) }\end{array}$} \\
\hline & $\begin{array}{l}\text { Strongly } \\
\text { disagree }\end{array}$ & Disagree & Neutral & Agree & $\begin{array}{l}\text { Strongly } \\
\text { agree }\end{array}$ \\
\hline Interest in profession. & $26(6.4)$ & $23(5.7)$ & $23(5.7)$ & $187(46.1)$ & $147(36.2)$ \\
\hline Aware about the importance of CPR in clinical practice. & $16(3.9)$ & $26(6.4)$ & $31(7.6)$ & $177(43.6)$ & $156(38.4)$ \\
\hline Confident in recognising a victim who needs CPR. & $10(2.5)$ & $23(5.7)$ & $31(7.6)$ & $182(44.6)$ & $160(39.4)$ \\
\hline Willing to provide mouth-to-mouth ventilation. & $36(8.9)$ & $111(27)$ & 73(18) & $131(32.3)$ & $55(13.5)$ \\
\hline $\begin{array}{l}\text { Knowledge and attitude of health professionals towards CPR can } \\
\text { affect patient outcome. }\end{array}$ & $11(2.7)$ & $18(4.4)$ & $31(7.6)$ & 163 (40.1) & 183 (45.1) \\
\hline All professionals should get BLS training before practising CPR. & $11(2.7)$ & $21(5.2)$ & $23(5.7)$ & $137(33.7)$ & $214(52.7)$ \\
\hline $\begin{array}{l}\text { Immediate access to defibrillator and resuscitation drugs in all } \\
\text { hospital areas. }\end{array}$ & $20(4.9)$ & $45(11.1)$ & $31(7.6)$ & $154(37.9)$ & $156(38.4)$ \\
\hline $\begin{array}{l}\text { Health professionals should be recertified on CPR course every } \\
2 \text { years. }\end{array}$ & $8(2.0)$ & $38(9.4)$ & 55 (13) & 132 (32.5) & 173 (42.6) \\
\hline BLS and ACLS should be given in undergraduate course. & $12(3.0)$ & $19(4.7)$ & $31(7.6)$ & $169(41.6)$ & $175(43.1)$ \\
\hline
\end{tabular}

ACLS, advanced cardiac life support; BLS, basic life support; CPR, cardiopulmonary resuscitation; HPs, health professionals. 
Table 5 Multivariable logistic regression showing factors associated with knowledge of health professionals at the University of Gondar Comprehensive Specialized Hospital, Northwest Ethiopia, 2018

\begin{tabular}{|c|c|c|c|c|}
\hline \multirow[b]{2}{*}{ Variables } & \multicolumn{2}{|c|}{ Knowledge status } & \multirow[b]{2}{*}{ Crude OR $(95 \% \mathrm{Cl})$} & \multirow[b]{2}{*}{ Adjusted OR $(95 \% \mathrm{Cl})$} \\
\hline & Good, n (\%) & Poor, n (\%) & & \\
\hline \multicolumn{5}{|l|}{ Sex } \\
\hline Male & $76(29.0)$ & $186(71.0)$ & 1.00 & 1.00 \\
\hline Female & $26(18.1)$ & $118(81.9)$ & 0.53 (0.32 to 0.89$)$ & 1.07 (0.55 to 2.06$)$ \\
\hline \multicolumn{5}{|l|}{ Age } \\
\hline $20-29$ & $42(17.1)$ & 204 (82.9) & 1.00 & 1.00 \\
\hline $30-39$ & $57(37.7)$ & $94(62.3)$ & 2.94 (1.84 to 4.70$)$ & 1.02 (0.48 to 2.18 ) \\
\hline$\geq 40$ & $3(33.3)$ & $6(66.7)$ & 2.42 (0.58 to 10.09$)$ & $1.66(0.21$ to 12.69$)$ \\
\hline \multicolumn{5}{|l|}{ Level of education } \\
\hline BSc degree & $38(13.4)$ & $245(86.6)$ & 1.00 & 1.00 \\
\hline MSc degree & $19(55.9)$ & $15(44.1)$ & 8.16 (3.82 to 17.43$)$ & 2.73 (0.91 to 7.32$)$ \\
\hline Resident & $21(33.3)$ & $42(66.7)$ & 3.22 (1.72 to 6.02$)$ & 0.75 (0.27 to 2.05$)$ \\
\hline Specialist & $16(61.5)$ & $10(38.5)$ & 10.31 (4.36 to 24.39 ) & 0.589 (0.16 to 2.01$)$ \\
\hline \multicolumn{5}{|l|}{ Work experience (years) } \\
\hline$<2$ & $5(9.4)$ & $48(90.6)$ & 1.00 & 1.00 \\
\hline $2-5$ & $48(20.1)$ & $191(79.9)$ & 2.41 (0.91 to 6.38$)$ & 2.03 (0.62 to 6.66$)$ \\
\hline$>5$ & $49(43.0)$ & $65(57.0)$ & 7.23 (2.68 to 19.53 ) & $5.02(1.25 \text { to } 20.20)^{\star}$ \\
\hline \multicolumn{5}{|l|}{ Number of work settings } \\
\hline Works only in one area & $40(14.4)$ & $237(85.6)$ & 1.00 & 1.00 \\
\hline Works in more than one area & $62(48.1)$ & $67(51.9)$ & 5.48 (3.38 to 8.87 ) & $6.52(2.76 \text { to } 15.41)^{\star}$ \\
\hline \multicolumn{5}{|l|}{ Exposure to cardiac arrest case } \\
\hline No & $33(17.7)$ & $153(82.3)$ & 1.00 & 1.00 \\
\hline Yes & $69(31.4)$ & $151(68.6)$ & 2.11 (1.32 to 3.39$)$ & $2.16(1.14 \text { to } 4.07)^{\star}$ \\
\hline \multicolumn{5}{|l|}{ CPR training } \\
\hline No & $25(10.1)$ & $223(89.9)$ & 1.00 & 1.00 \\
\hline Yes & $77(48.7)$ & $81(51.3)$ & $8.48(5.05$ to 14.23$)$ & $2.76(1.40 \text { to } 5.42)^{*}$ \\
\hline \multicolumn{5}{|l|}{ Reading CPR guidelines } \\
\hline No & $20(7.8)$ & $236(92.2)$ & 1.00 & 1.00 \\
\hline Yes & $82(54.7)$ & $68(45.3)$ & 14.22 (8.42 to 24.86$)$ & $5.57(2.76 \text { to } 11.20)^{\star}$ \\
\hline
\end{tabular}

Cox and Snell R-squared: 0.318 .

*Significantly associated with knowledge of health professionals $(p<0.05) ; 1.00$ : reference.

CPR, cardiopulmonary resuscitation.

the current study, which was a significant factor in determining health professionals' level of knowledge.

In this study, work experience has a strong association with participants' knowledge towards CPR. This finding is consistent with a study done in Ethiopia aimed to assess the knowledge and practices of nurses in two hospitals. ${ }^{27}$ It is known that knowledge can be acquired through experience, so that individuals who had long clinical experience had high probability of getting CPR cases, leading them to read, search and understand CPR. However, contradicting findings were reported from Kuwait, where participants at lower career hierarchy and with less than 10 years of clinical experience had significantly higher knowledge scores in comparison with the more experienced ones. This might be because, without sufficient training and practice, a significant amount of theoretical information will be forgotten after 12 months, and there will not be any remaining adequate theoretical practical skills. ${ }^{16}$

In the current study, participants working in different wards were more knowledgeable compared with participants working in only one ward. This result is in agreement with a Turkey study done to evaluate nurses' and doctors' knowledge of basic and advanced life support. ${ }^{34}$ This might be because health professionals working in more than one work area and in high-risk areas had more repeated exposures to cardiac arrest cases, and as a result they acquire good theoretical knowledge and positive 
Table 6 Multivariable logistic regression showing factors associated with attitude of health professionals at the University of Gondar Comprehensive Specialized Hospital, Northwest Ethiopia, 2018

\begin{tabular}{|c|c|c|c|c|}
\hline \multirow[b]{2}{*}{ Variables } & \multicolumn{2}{|c|}{ Attitude status } & \multirow[b]{2}{*}{ Crude OR $(95 \% \mathrm{Cl})$} & \multirow[b]{2}{*}{ Adjusted OR $(95 \% \mathrm{Cl})$} \\
\hline & Good, n (\%) & Poor, n (\%) & & \\
\hline \multicolumn{5}{|l|}{ Sex } \\
\hline Male & $172(65.6)$ & $90(34.4)$ & 1.00 & 1.00 \\
\hline Female & $75(52.1)$ & $69(47.9)$ & 0.56 (0.37 to 0.86$)$ & $0.72(0.45$ to 1.14$)$ \\
\hline \multicolumn{5}{|l|}{ Age } \\
\hline 20-29 & $141(57.1)$ & $106(42.9)$ & 1.00 & 1.00 \\
\hline 30-39 & $102(68.0)$ & $48(32.0)$ & 1.59 (1.04 to 2.44$)$ & 1.42 (0.88 to 2.28$)$ \\
\hline$\geq 40$ & $4(44.4)$ & $5(55.6)$ & 0.60 (0.15 to 2.29$)$ & 0.76 (0.19 to 3.09$)$ \\
\hline \multicolumn{5}{|l|}{ Number of work settings } \\
\hline Works only in one area & $143(49.8)$ & $144(50.2)$ & 1.00 & 1.00 \\
\hline Works in more than one area & $104(87.4)$ & $15(12.6)$ & 6.98 (3.87 to 12.57$)$ & 5.55 (0.98 to 10.3$)$ \\
\hline \multicolumn{5}{|l|}{ Level of education } \\
\hline BSc degree & $184(65.0)$ & $99(35.0)$ & 1.00 & 1.00 \\
\hline MSc degree & $19(55.9)$ & $15(44.1)$ & $0.68(0.33$ to 1.40$)$ & 1.12 (0.51 to 2.43$)$ \\
\hline Resident & $27(42.9)$ & $36(57.1)$ & 0.40 (0.23 to 0.73$)$ & 0.71 (0.39 to 1.31$)$ \\
\hline Specialist & $17(65.4)$ & $9(34.6)$ & 1.01 (1.43 to 2.36$)$ & 1.36 (0.55 to 3.39$)$ \\
\hline \multicolumn{5}{|l|}{ CPR training } \\
\hline No & $138(55.6)$ & $110(44.4)$ & 1.00 & 1.00 \\
\hline Yes & $109(69.0)$ & $49(31.0)$ & 1.77 (1.16 to 2.69$)$ & $1.74(1.42 \text { to } 3.53)^{*}$ \\
\hline \multicolumn{5}{|l|}{ Reading CPR guidelines } \\
\hline No & $131(51.2)$ & $125(48.8)$ & 1.00 & 1.00 \\
\hline Yes & $116(77.3)$ & $34(22.7)$ & 3.25 (2.06 to 5.12$)$ & $2.74(1.55 \text { to } 4.85)^{\star}$ \\
\hline
\end{tabular}

Cox and Snell R-squared: 0.175.

${ }^{*}$ Significantly associated with attitude of health professionals $(p<0.05) ; 1.00$ : reference.

CPR, cardiopulmonary resuscitation.

attitude. This is also supported by UK resuscitation guidelines, which state that staff who had more exposures to different patient care areas may have more advanced resuscitation knowledge and skills. ${ }^{35}$

CPR training was significantly associated with health professionals' knowledge towards CPR. Study participants who had taken CPR training were more knowledgeable than their counterparts. This finding is in line with a study in Ethiopia. ${ }^{27}$ Other studies also reported that taking CPR training results in health professionals having good knowledge about CPR. ${ }^{1833336}$ This might be because health professionals who had taken regular CPR training acquired up-to-date information about CPR and there was no fad in knowledge, and as a result they had good knowledge of CPR.

Previous exposure to cardiac arrest cases significantly influenced the CPR knowledge of health professionals. Those who have been exposed to cardiac arrest cases were more knowledgeable than those who have not been exposed, which is in agreement with the results of a Nepal study on BLS knowledge and attitude of medical professionals. ${ }^{23}$ This might be because knowledge can be acquired from repeated exposures to cardiac arrest case management and experience.

In this study there was also a significant association between health professionals' knowledge and reading CPR guidelines. The finding in this study showed that health professionals who had the chance to read CPR guidelines were more knowledgeable than those who did not not read CPR guidelines. As supported by studies, reading can independently affect knowledge of professionals. ${ }^{37} 38$ This is because health professionals who read CPR guidelines had better understanding of the theoretical and practical aspects of CPR and they can easily remember CPR principles and have up-to-date knowledge about CPR working guidelines.

In this study, the attitude level of health professionals towards CPR was $60.8 \%$ (95\% CI 55.9 to 65.5). The finding is lower than a study done among Pakistan healthcare providers aimed to assess the retention of knowledge and skills in BLS (84.8\%). ${ }^{18}$ The possible explanation for this variation might be that the participants of the Pakistan study had regular training every 2 years, which is an advantage since health professionals 
are able to update their knowledge, which might influence their attitude.

Study participants who had taken CPR training had good attitude compared with their counterparts. This finding is in agreement with a study in Pakistan healthcare providers aimed to assess the retention of knowledge and skills in BLS. ${ }^{18}$ This might be because healthcare professionals who had taken regular CPR training acquired up-to-date information about CPR and that professionals may share personal experiences with each other.

In this study, health professionals who read CPR guidelines are 2.80 times more likely to have good attitude than those who did not read CPR guidelines. As reported from different studies,${ }^{39}{ }^{40}$ health professionals' attitude might change with training incentives and reading. Due to this possible reason, reading CPR working guidelines gave confidence and positive attitude towards CPR among health professionals.

This study has its own limitations. First, the study is cross-sectional and cannot establish cause and effect relationship. Second, there might be social desirability bias among respondents in answering the knowledge and attitude questions. Finally, the study did not include the practice of CPR, and the findings may not be generalised to all health professionals in the Amhara Region.

In conclusion, this study confirmed that the level of knowledge and attitude of health professionals towards adult CPR was suboptimal, according to the AHA reference for CPR certification. Taking CPR training and reading CPR guidelines were significantly associated with both good knowledge and attitude of health professionals towards CPR, while health professionals' work experience, exposure to cardiac arrest case and work exposure were significantly associated with good knowledge. Therefore, regular CPR training and reading CPR guidelines are recommended to increase the level of knowledge and attitude of health professionals towards adult CPR. Also, updating CPR guidelines and providing access for every health professional are crucial. Finally, conducting similar studies that include the level of skills of professionals by simulation-based or real cardiac arrest cases is recommended.

\section{Twitter Nigussie Simeneh Endalew @Nigussie Simeneh Endalew@NEndalew}

Acknowledgements The authors would like to acknowledge the University of Gondar for approval of ethical clearance and giving the chance to conduct this study. The authors' special gratitude goes to the study participants and data collectors. Finally, the authors would like to acknowledge the Department of Anesthesia and all their friends for their kind support.

Contributors AHKGE conceived the study, developed the tool, coordinated the data collection activity and carried out the statistical analysis. HYT and NSE participated in the design of the study, tool development, data collection supervision and drafting the manuscript. ATM participated in the design of the study and tool development, performed the statistical analysis, and reviewed and edited the manuscript. All authors read and approved the final manuscript.

Funding The authors have not declared a specific grant for this research from any funding agency in the public, commercial or not-for-profit sectors.

Competing interests None declared.
Patient and public involvement Patients and/or the public were not involved in the design, or conduct, or reporting, or dissemination plans of this research.

Patient consent for publication Obtained.

Ethics approval Ethical clearance was obtained from the ethical review committee of the School of Medicine, College of Medicine and Health Science, University of Gondar. Informed consent was obtained from each study subject after clear explanation about the objective and purpose and participants have the right to refuse to participate in the study. Confidentiality was ensured by avoiding personal identification on the questionnaire and by keeping the questionnaire locked.

Provenance and peer review Not commissioned; externally peer reviewed.

Data availability statement Data are available upon reasonable request. All data relevant to the study are included in the article or uploaded as supplementary information. Due to ethical restrictions and privacy concerns, a data set is available upon request from ATM (abrahamtm2006@gmail.com).

Open access This is an open access article distributed in accordance with the Creative Commons Attribution Non Commercial (CC BY-NC 4.0) license, which permits others to distribute, remix, adapt, build upon this work non-commercially, and license their derivative works on different terms, provided the original work is properly cited, appropriate credit is given, any changes made indicated, and the use is non-commercial. See: http://creativecommons.org/licenses/by-nc/4.0/.

\section{ORCID iDs}

Abraham Tarekegn Mersha http://orcid.org/0000-0002-5548-0289

Nigussie Simeneh Endalew http://orcid.org/0000-0001-7632-5707

\section{REFERENCES}

1 Nolan JP, Soar J, Zideman DA, et al. European resuscitation Council guidelines for resuscitation 2010 section 1. executive summary. Resuscitation 2010;81:1219-76.

2 Chugh SS, Reinier K, Teodorescu C, et al. Epidemiology of sudden cardiac death: clinical and research implications. Prog Cardiovasc Dis 2008; 51:213-28.

3 Feero S, Hedges JR, Stevens P. Demographics of cardiac arrest: association with residence in a low-income area. Acad Emerg Med 1995;2:11-16.

4 Soo L, Huff N, Gray D, et al. Geographical distribution of cardiac arrest in Nottinghamshire. Resuscitation 2001;48:137-47.

5 Lockey D, Crewdson K, Davies G. Traumatic cardiac arrest: who are the survivors? Ann Emerg Med 2006;48:240-4.

6 Mehra R. Global public health problem of sudden cardiac death. $J$ Electrocardiol 2007;40:S118-22.

7 Go AS, Mozaffarian D, Roger VL, et al. Heart disease and stroke statistics--2013 update: a report from the American Heart Association. Circulation 2013;127:e6-245.

8 Sreevastava DK, Roy PK, Dass SK, et al. Cardio-pulmonary Resuscitation : an overview of Recent Advances in Concepts and Practices. Med J Armed Forces India 2004;60:52-8.

9 Association AH. Highlights of the 2015 American heart association guidelines update for CPR and ECC. Dallas, USA, 2015.

10 Hodges UM, Adams AP. Guidelines for resuscitation. Survey of Anesthesiology 1994;38:301.

11 Nambiar M, Nedungalaparambil NM, Aslesh OP. Is current training in basic and advanced cardiac life support (BLS \& ACLS) effective? A study of BLS \& ACLS knowledge amongst healthcare professionals of North-Kerala. World J Emerg Med 2016;7:263.

12 Ralapanawa DMPUK, Jayawickreme KP, Ekanayake EMM, et al. A study on the knowledge and attitudes on advanced life support among medical students and medical officers in a tertiary care hospital in Sri Lanka. BMC Res Notes 2016;9:462.

13 Kleinman ME, Brennan EE, Goldberger ZD, et al. Part 5: adult basic life support and cardiopulmonary resuscitation quality. Circulation 2015;132:S414-35.

14 Cooper S, Johnston E, Priscott D, et al. Immediate life support (ILS) training impact in a primary care setting? Resuscitation 2007;72:92-9.

15 Ritter G, Wolfe RA, Goldstein S, et al. The effect of bystander CPR on survival of out-of-hospital cardiac arrest victims. Am Heart $J$ 1985;110:932-7.

16 Alkandari SA, Alyahya L, Abdulwahab M. Cardiopulmonary resuscitation knowledge and attitude among General dentists in Kuwait. World J Emerg Med 2017;8:19.

17 Chew F Z A W M N KS, Mohd Hashairi F, Ida Zarina Z, et al. A survey on the knowledge, attitude and confidence level of adult cardiopulmonary resuscitation among junior doctors in hospital 
Universiti Sains Malaysia and hospital Raja Perempuan Zainab II, Kota Bharu, Kelantan, Malaysia. Med J Malaysia 2011;66:56-9.

18 Ilyas R, KS-e Z, Pradhan N, et al. Retention of knowledge and skills of basic life support among health care providers trained in tertiary care hospital. Pakistan Heart Journal 2014;47.

19 Cheskes L, Dainty K, Beaton D. Assessing public perceptions of cardiopulmonary resuscitation and bystander willingness to act in out-of-hospital cardiac arrest: a qualitative study: am heart Assoc, 2013.

20 Ong ME, Yap S, Chan KP, et al. Knowledge and attitudes towards cardiopulmonary resuscitation and defibrillation amongst Asian primary health care physicians. Open Access Emerg Med 2009:1:11-20.

21 Howell P, Tennant I, Augier R, et al. Physicians' knowledge of cardiopulmonary resuscitation guidelines and current certification status at the university hospital of the West Indies, Jamaica. West Indian Med J 2014;63:739.

22 García ABS, Alemán JLF, Pérez NA, et al. Assessment of the knowledge level and its relevance in terms of CPR in medical personnel of the hospital emergency medical system of the autonomous community of the region of Murcia/Valoración del nivel de conocimientos Y SU adecuación en materia de RCP en EI personal sanitario de Los servicios de urgencias hospitalarios de la Comunidad Autónoma de la Región de Murcia. Enfermeria Global 2015;14.

23 Roshana S, Kh B, Rm P, Batajoo K, Piryani R, et al. Basic life support: knowledge and attitude of medical/paramedical professionals. World J Emerg Med 2012;3:141.

24 Olajumoke TO, Afolayan JM, Raji SA, et al. Cardiopulmonary resuscitation - knowledge, attitude \& practices in osun state, Nigeria. J West Afr Coll Surg 2012;2:23.

25 Govender K, Rangiah C, Ross A, et al. Retention of knowledge of and skills in cardiopulmonary resuscitation among healthcare providers after training. South African Family Practice 2010;52:459-62.

26 Alam T, Jamil Khattak Y, Anwar M, et al. Basic life support: a questionnaire survey to assess proficiency of radiologists and radiology residents in managing adult life support in cardiopulmonary arrest and acute anaphylactic reaction. Emerg Med Int 2014;2014:1-4.

27 Mekonnen M, Birhanu Z, Kassa $\mathrm{H}$, et al. A cross sectional study on knowledge, practice and associated factors towards basic life support among nurses working in Amhara region referral hospitals. Hospice \& Palliative Medicine International Journal 2018;2:123-30.
28 ECC Committee, Subcommittees and Task Forces of the American Heart Association. 2005 American heart association guidelines for cardiopulmonary resuscitation and emergency cardiovascular care. Circulation 2005:112.

29 Botha L, Geyser MM, Engelbrecht A. Knowledge of cardiopulmonary resuscitation of clinicians at a South African tertiary hospital. $S$ Afr Fam Pract 2012;54:447-54.

30 Keenan M, Lamacraft G, Joubert G. A survey of nurses' basic life support knowledge and training at a tertiary hospital. African Journal of Health Professions Education 2009;1:3-7.

31 Onyeaso AO, Imogie A. Attitude towards cardiopulmonary resuscitation among some secondary school students in rivers state, Nigeria. Br J Educ 2014;2:37-43.

32 Burkhardt JN, Glick JE, Terndrup TE. Effect of prior cardiopulmonary resuscitation knowledge on compression performance by hospital providers. West J Emerg Med 2014;15:404-8.

33 Weji BG, Goshu EM, Melese KG. Assessment of knowledge, attitude and associated factors of cardiopulmonary resuscitation among anesthetists working in governmental and private hospitals in Addis Ababa, Ethiopia: institutional based cross-sectional study. International Journal of Medicine and Medical Sciences 2017;9:17-21.

34 Passali C, Pantazopoulos I, Dontas I, et al. Evaluation of nurses' and doctors' knowledge of basic \& advanced life support resuscitation guidelines. Nurse Educ Pract 2011;11:365-9.

35 Truhláŕ A, Deakin CD, Soar J, et al. European resuscitation Council guidelines for resuscitation 2015: section 4. cardiac arrest in special circumstances. Resuscitation 2015;95:148-201.

36 Rajeswaran L, Ehlers VJ. Cardiopulmonary resuscitation knowledge and skills of registered nurses in Botswana. Curationis 2014;37:1-7.

37 Muijselaar MML, de Jong PF. The effects of updating ability and knowledge of reading strategies on reading comprehension. Learn Individ Differ 2015;43:111-7.

38 Mar R, Djikic M, Oatley K. Effects of reading on knowledge, social abilities, and selfliood. Directions in empirical literary studies: in honor of Willie van peer, 2008: 127.

39 Touza Garma C, Garma CT. Influence of health personnel's attitudes and knowledge in the detection and reporting of elder abuse: an exploratory systematic review. Psychosocial Intervention 2017;26:73-91.

40 Rise MB, Steinsbekk A. Long term effect on professionals' knowledge, practice and attitudes towards user involvement four years after implementing an organisational development plan: a controlled study. PLoS One 2016;11:e0150742. 